Supplement of Hydrol. Earth Syst. Sci., 25, 1-15, 2021

https://doi.org/10.5194/hess-25-1-2021-supplement

(C) Author(s) 2021. This work is distributed under

the Creative Commons Attribution 4.0 License.

(c) (1)

Supplement of

\title{
A field evidence model: how to predict transport in heterogeneous aquifers at low investigation level
}

\author{
Alraune Zech et al. \\ Correspondence to: Alraune Zech (a.zech@uu.nl)
}

The copyright of individual parts of the supplement might differ from the CC BY 4.0 License. 


\section{Overview on field data at MADE site}

Table 1 provides a list of subsurface investigation activities performed at the MADE site located on the Columbus Air Force Base, Mississippi. Monitoring campaigns at the nearby 1-Ha test site, e.g. Young [1995]; Herweijer [1997] are not included.

Table 1: Summary of observation data on hydraulic conductivity at MADE site with number of campaigns in brackets.

\begin{tabular}{ll}
\hline \hline Method of Measurement & References \\
\hline \hline Groundwater level monitoring (1) & Boggs et al. $[1990]$ \\
Soil sampling (2) & Boggs et al. $[1990] ;$ Rehfeldt et al. $[1992] ;$ \\
& Bianchi et al. $[2011 \mathrm{~b}]$ \\
Pumping tests (1) & Boggs et al. $[1990]$ \\
Slug tests (1) & Boggs et al. $[1990]$ \\
Packer tests (1) & Boggs et al. $[1990]$ \\
Permeameter tests (1) & Boggs et al. $[1990] \quad$ \\
Borehole flowmeter (3) & Rehfeldt et al. $\quad[1989] ; \quad$ Boggs et al. \\
& {$[1990,1993,1995]$} \\
DPIL, DPP (2) & Liu et al. $[2009] ;$ Bohling et al. $[2012]$ \\
Surface geophysics (2) & Boggs et al. $[1990] ;$ Bowling et al. $[2005]$ \\
Natural gradient tracer test (MADE- & Boggs et al. $[1992] ;$ Rehfeldt et al. $[1992] ;$ \\
1, MADE-2, MADE-3) & Boggs et al. $[1993,1995] ;$ Julian et al. $[2001]$ \\
Force gradient tracer test (MADE-4, & Liu et al. $[2010] ;$ Bianchi et al. $[2011 a]$ \\
MADE-5) & \\
\hline \hline
\end{tabular}

\section{Details on Hydraulic Conductivity Structure A}

Module (A) for MADE comprises of two deterministic zones whose presence is indicated by the piezometric surface map (article Figure 1a) and two large scale pumping tests (article Figure 3a) [Boggs et al., 1992]. Zone $Z_{1}$ is an area of low conductivity from upstream of the tracer input location to $x=20 \mathrm{~m}$ downstream with a specific mean value of $\bar{K}_{Z 1}=2 e-6 \mathrm{~m} / \mathrm{s}$. Zone $Z_{2}$ is an area upstream beyond $20 \mathrm{~m}$ from the source location with a high mean conductivity of $\bar{K}_{\mathrm{Z} 2}=2 e-4 \mathrm{~m} / \mathrm{s}$.

The value of $\bar{K}_{\mathrm{Z} 2}$ is the outcome of a large scale pumping test [Boggs et al., 1990]. The test was performed about $60 \mathrm{~m}$ downstream of the source location within the distribution area of the tracer plume (article Figure 3a). Conductivity estimates for different observation wells reveal little spread. Thus, the test's support area is of relatively uniform high conductivity.

The conductivity in zone $Z_{1}$ is critical because the value in the vicinity of the tracer injection area determines the early plume development. Boggs et al. [1990] reported a mean conductivity of $2 e-5 \mathrm{~m} / \mathrm{s}$ for a large scale pumping test AT1 which was performed about $90 \mathrm{~m}$ upstream of the source location (article Figure 3a), thus outside of the tracer distribution area. The conductivity values from the individual observations wells show a large spread indicating strong heterogeneity within this area. Furthermore, pumping tests tend to emphasize the impact of high conductivity areas, possibly overestimating the mean conductivity. 
Since the tracer injection site is not located within the support volume of the pumping test AT1, we consider additional data taken during tracer injection. Water levels were monitored manually in the injection wells and seven observation wells close to the source [Boggs et al., 1990]. A pressure head increase of more then $0.5 \mathrm{~m}$ up to $0.64 \mathrm{~m}$ was observed in all injection wells. Combining the head increase with the mean injection rate of $Q_{i n}=1.15 e-5 \mathrm{~m}^{3} / \mathrm{s}$ indicates an average conductivity of $\bar{K}_{Z 1}=2 e-6 \mathrm{~m} / \mathrm{s}$ in the source area.

\section{Details on parametric uncertainty for binary structure $A+B$}
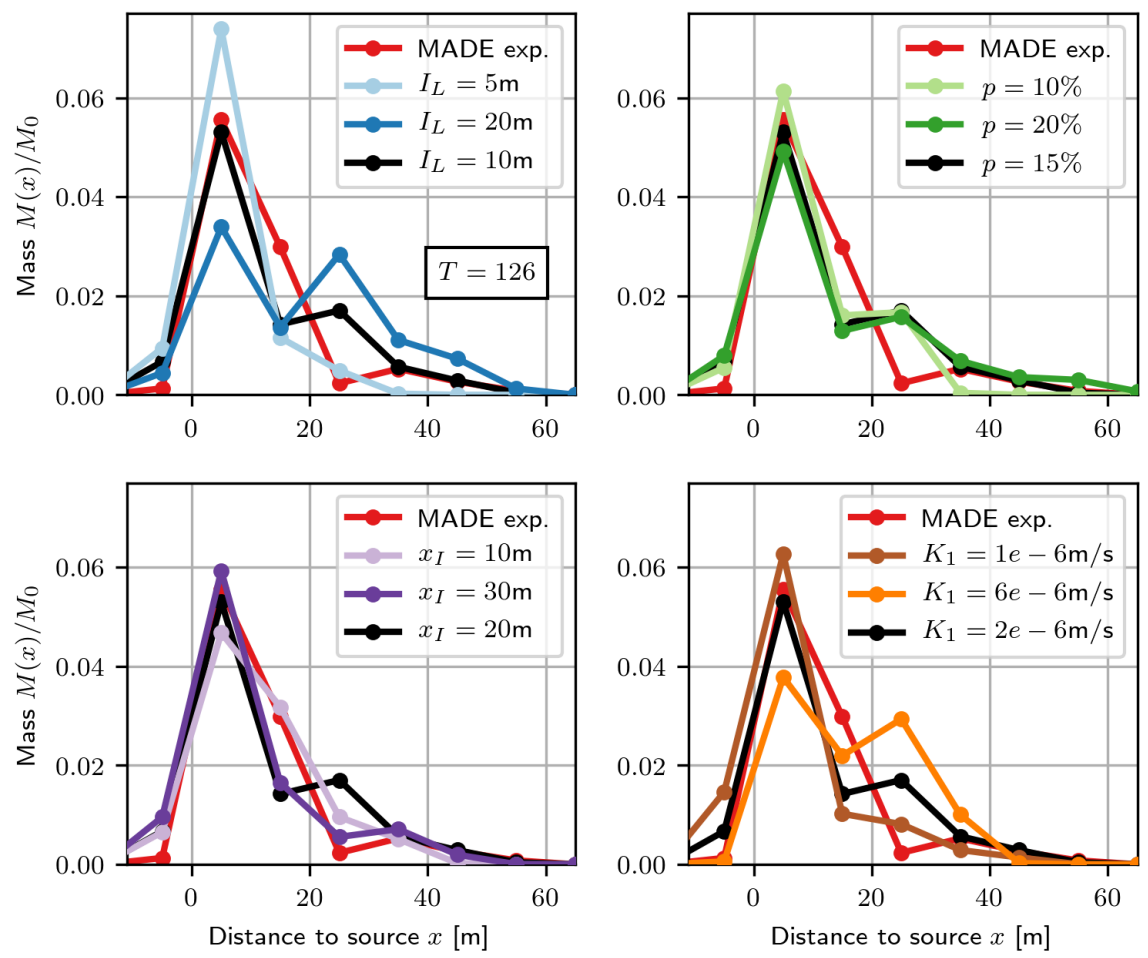

Figure 1: Mass distribution at $T=126$ days for conductivity concept $(\mathrm{A}+\mathrm{B})$ for various input parameter combinations of inclusion structure: inclusion length $I_{L}$, volume fraction of inclusions $p$, distance of zone interface $x_{I}$ to source location and mean conductivity $K_{1}$ of zone $Z_{1}$ (source area). Mass distribution for standard parameters in black. MADE experiment observations in red.

Figure 1 shows the longitudinal mass distributions for different combination of input parameters for the binary inclusion structure $(\mathrm{A}+\mathrm{B})$. Within every panel, one parameter was varied in comparison to the standard parameter choice of $K_{Z 1}=2 e-6 \mathrm{~m} / \mathrm{s} ; K_{Z 2}=2 e-4 \mathrm{~m} / \mathrm{s} ; p=15 \%$; $I_{l}=10 \mathrm{~m} ; I_{v}=0.5 \mathrm{~m} ;$ and $x_{I}=20 \mathrm{~m}$.

The inclusion length and the choice of the conductivity contrast between the zones show the highest impact. The later was expected as the mean conductivity determines the average flow velocity and thus the peak location and plume width. The horizontal inclusion length $I_{h}$ determines the connectivity of the source area to the high conducitivity zone. Thus, the larger $I_{h}$ the higher is the amount of mass transported downstream, visible at the lower mass peak value at $x=5 \mathrm{~m}$ and higher second peak at $x=25 \mathrm{~m}$ for $I_{h}=20 \mathrm{~m}$. The uncertainty bands in (article) Figures $6 \mathrm{~b}$ and 7 coincide with the upper and lower range of ensemble results for $I_{h}=5 \mathrm{~m}$ and $I_{h}=20 \mathrm{~m}$. 
Other parameters as the distance of the interface to the injection location $x_{I}$, the volume fraction of inclusion $p$ (Figure 1) as well as the vertical inclusion length $I_{v}$ have minor effects, at least within the range tested. Similarly, the choice of sub-scale heterogeneity parameters is secondary since the inclusion structure dominates the mass distribution. We tested values up to $\sigma^{2}=2$ and found nearly no difference to the results of the standard setting for the conductivity concept $(\mathrm{A}+\mathrm{B}+\mathrm{C})$.

In general, all parameter combinations within the value ranges determined for MADE show a similar mass distribution pattern. In this regard, the binary structure is very stable towards parametric uncertainty.

\section{Details on flow and transport model settings}

The simulation domain is a $2 \mathrm{D}$ cross section with $x \in[-20,200] \mathrm{m}$ and $z \in[52,62] \mathrm{m}$ generously comprising the area of the MADE-1 tracer experiment [Boggs et al., 1992]. The grid has a resolution of $\Delta x=0.25 \mathrm{~m}$ and $\Delta z=0.05 \mathrm{~m}$. The temporal resolution is one day, with hourly resolution of the first 10 days. Flow boundary conditions are no flow at the top and the bottom of the domain and a constant head of $h=63 \mathrm{~m}$ at the left and $h=62.34 \mathrm{~m}$ at the right, resulting in a mean head gradient of $J=0.003$. The porosity was set to 0.31 .

The tracer input takes place at a central injection well located at $x=0$ with a screen of $0.6 \mathrm{~m}$ length at $z \in[57.2,57.8] \mathrm{m}$. Tracer was injected over $48.5 \mathrm{~h}$ with forced input conditions. The injection rate is $Q_{i n}=1.166 e-5 \mathrm{~m}^{3} / \mathrm{s}$. Solute injection mode is flux related, which take the distribution of conductivity at the injection well into account. Specifically, injection along the well distributes proportional to the local conductivity. This way mass mostly enters preferential zones of high conductivity which represents best natural injection conditions at heterogeneous sites such as MADE. The values have been adapted from the experimental setting reported by Boggs et al. [1992]: "The method of injecting the tracer solution into the aquifer was designed, to the extent possible, to produce a uniform pulse release of tracers into approximately the middle of the saturated zone of the alluvial aquifer with a minimal amount of disturbance to the natural flow field. Five 5.2-cm-diameter injection wells spaced $1 \mathrm{~m}$ apart in a linear array, each screened between depths of 7.4-8.0 m below ground surface, were used to introduce the tracer solution into the aquifer. Beginning on October 28, 1986, $10.07 \mathrm{~m}^{3}$ of groundwater containing $2500 \mathrm{mg} / \mathrm{L}$ of bromide and $400 \mathrm{mg} / L$ of each of the FBA tracers was metered into the the injection wells at a uniform rate over a period of 48.5 hours." This way a plume front was created which is described by the advection-dispersion-equation under uniform flow boundary conditions and a transport initial condition of a plane. Under these initial and boundary conditions, the movement of the plume centre can be dimensionally reduced. We model the plume development along the vertical cross section of the central injection well, which covers a fifth of the total injection rate, thus $Q_{\text {in }}=1.166 e-5 \mathrm{~m}^{3} / \mathrm{s}$.

\section{Details on model dimensionality}

The model setup we present is $2 \mathrm{D}$ although in many applications of heterogeneous hydraulic conductivity it is well known that dimensionality (i.e. 2D vs. 3D) can make a significant difference 


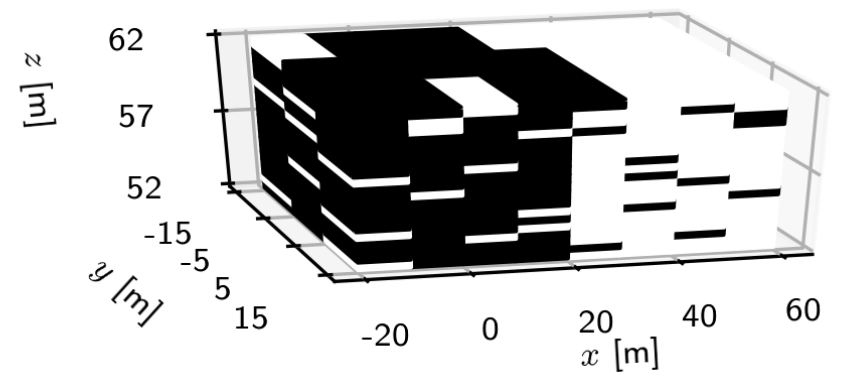

Figure 2: Realization of a three dimensional binary inclusion structure with $p=15 \%$ inclusions and inclusion lengths $I_{y}=I_{x}=10 \mathrm{~m}, I_{z}=0.5-1 \mathrm{~m}$. Black areas corresponds to low and white to high conductivity. Length is reduced to $x=60 \mathrm{~m}$, source is located at $x=0$.

in the flow and transport pattern [Zinn and Harvey, 2003; Jankovic et al., 2017].

To check the dimensionality effect, we performed simulations for a 3D conductivity conceptualizations with binary inclusion for the MADE transport experiment. Therefore, we generated a reduced set of realizations of binary inclusion, which now also expand in the transverse horizontal direction. The domain covers a 3D grid with dimensions $x \in[-20,200] \mathrm{m}, z \in[52,62] \mathrm{m}$ (similar to the 2D domain) and $y \in[-15,15] \mathrm{m}$ and a resolutions of $d x=0.5 \mathrm{~m}, d y=1.0 \mathrm{~m}$ and $d z=0.25 \mathrm{~m}$. The inclusion structure is conceptually the same as for the $2 \mathrm{D}$ cross section, now expanding also in $y$-direction with an inclusion length of $I_{y}=I_{x}$. The inclusion length $I_{y}$ was chosen identical to the one in $x$-direction given no clear indication of horizontal anisotropy by the head and conductivity data. Figure 2 displays a realization of the three dimensional binary inclusion structure.

We found almost no differences between 2D and 3D results of flow patterns and mass distribution pattern. We relate that to the conceptualization of the binary structure: Assuming horizontal isotropy, the inclusion lengths are identical in both horizontal directions. Thus, extending the binary structure in $y$-direction perpendicular to main flow is like combining many copies of the $2 \mathrm{D}$ cross section. The structural pattern does not change over the length of the horizontal inclusion $I_{y}$, e.g. 5, 10 or even $20 \mathrm{~m}$. Consequently, deviations of flow in the horizontal direction perpendicular to the head gradient are negligible. Thus, there is no real change in the flow pattern, in mean velocity and preferential flow between binary structures in 2D and 3D.

We relate the very light differences between $2 \mathrm{D}$ and $3 \mathrm{D}$ results to a slight increase of mean flow velocity due to a higher connectivity of inclusion in 3D. However, this is only relevant over a large domain and does hardly impact the local flow pattern in the area where transport takes place.

Dimensionality is important in (purely) log-normal random fields, where uniform flow through heterogeneous fields shows higher effective $K$ values in 3D than 2D. Here, conductivity values change gradually in all directions. Thus, adding a third dimension perpendicular to the main flow direction allows to circumvent areas of low conductivity and thus increases the effective mean flow velocity. In the binary material, there are no gradual changes. A layer of low conductivity in horizontal direction extends in both horizontal directions, being an obstacle for the flow and 
not allowing to circumvent low-K regions by deviating from the main flow direction.

We like to stress, that when applying the proposed heterogeneity conceptualizations for modelling flow and transport in other application, it should be considered to setup the model in 3D. This is particular relevant when heterogeneity is dominated by a log-normal distribution (modules $\mathrm{C}$ ). A reduction in complexity by using $2 \mathrm{D}$ models is warranted when conductivity conceptualizations is dominated by the binary structure (module B).

\section{References}

Bianchi, M., C. Zheng, G. R. Tick, and S. M. Gorelick, Investigation of Small-Scale Preferential Flow with a Forced-Gradient Tracer Test, Ground Water, 49(4), 503-514, doi:10.1111/j.17456584.2010.00746.x, 2011a.

Bianchi, M., C. Zheng, C. Wilson, G. R. Tick, G. Liu, and S. M. Gorelick, Spatial connectivity in a highly heterogeneous aquifer: From cores to preferential flow paths, Water Resour. Res., 47(5), W05,524, doi:10.1029/2009WR008966, 2011 b.

Boggs, J. M., S. Young, D. Benton, and Y. Chung, Hydrogeologic Characterization of the MADE Site, Tech. Rep. EN-6915, EPRI, Palo Alto, CA, 1990.

Boggs, J. M., S. C. Young, L. M. Beard, L. W. Gelhar, K. R. Rehfeldt, and E. E. Adams, Field study of dispersion in a heterogeneous aquifer: 1. Overview and site description, Water Resour. Res., 28(12), 3281-3291, doi:10.1029/92WR01756, 1992.

Boggs, J. M., L. M. Beard, W. Waldrop, T. B. Stauffer, W. G. MacIntyre, and C. P. Antworth, Transport of Tritium and Four Organic Compounds During a Natural-Gradient Experiment (MADE-2), Tech. Rep. TR-101998, EPRI, Palo Alto, CA, 1993.

Boggs, J. M., J. Schroeder, and S. Young, Data to support model development for natural attenuation study, Tech. Rep. WR28-2-520-197, TVA Engineering Laboratory, Tennessee Valley Authority, Norris, Tennessee, 1995.

Bohling, G. C., G. Liu, S. J. Knobbe, E. C. Reboulet, D. W. Hyndman, P. Dietrich, and J. J. Butler, Geostatistical analysis of centimeter-scale hydraulic conductivity variations at the MADE site, Water Resour. Res., 48, W02,525, doi:10.1029/2011WR010791, 2012.

Bowling, J. C., A. B. Rodriguez, D. L. Harry, and C. Zheng, Delineating alluvial aquifer heterogeneity using resistivity and GPR data, Ground Water, 43(6), 890-903, doi:10.1111/j.17456584.2005.00103.x, 2005.

Herweijer, J. C., Sedimentary heterogeneity and flow towards a well, Ph.D. thesis, Vrije Universiteit Amsterdam, Amsterdam, 1997.

Jankovic, I., M. Maghrebi, A. Fiori, and G. Dagan, When good statistical models of aquifer heterogeneity go right: The impact of aquifer permeability structures on $3 \mathrm{~d}$ flow and transport, Adv. Water Resour., 100, 199-211, doi:10.1016/j.advwatres.2016.10.024, 2017. 
Julian, H. E., J. M. Boggs, C. Zheng, and C. E. Feehley, Numerical simulation of a natural gradient tracer experiment for the natural attenuation study: Flow and physical transport, Ground Water, 39(4), 534-545, doi:10.1111/j.1745-6584.2001.tb02342.x, 2001.

Liu, G., J. J. Butler, G. C. Bohling, E. Reboulet, S. Knobbe, and D. W. Hyndman, A new method for high-resolution characterization of hydraulic conductivity, Water Resour. Res., 45(8), W08,202, doi:10.1029/2009WR008319, 2009.

Liu, G., C. Zheng, G. R. Tick, J. J. Butler, and S. M. Gorelick, Relative importance of dispersion and rate-limited mass transfer in highly heterogeneous porous media: Analysis of a new tracer test at the Macrodispersion Experiment (MADE) site, Water Resour. Res., 46(3), W03,524, doi:10.1029/2009WR008430, 2010.

Rehfeldt, K. R., P. Hufschmied, L. W. Gelhar, and M. Schaefer, Measuring hydraulic conductivity with the borehole flowmeter, Tech. Rep. EN-6511, EPRI, Palo Alto, CA, 1989.

Rehfeldt, K. R., J. M. Boggs, and L. W. Gelhar, Field study of dispersion in a heterogeneous aquifer: 3. Geostatistical analysis of hydraulic conductivity, Water Resour. Res., 28(12), 33093324, doi:10.1029/92WR01758, 1992.

Young, S., Characterization of high-K pathways by borehole flowmeter and tracer tests, Ground Water, 33(2), 311-318, doi:10.1111/j.1745-6584.1995.tb00286.x, 1995.

Zinn, B., and C. F. Harvey, When good statistical models of aquifer heterogeneity go bad: A comparison of flow, dispersion, and mass transfer in connected and multivariate Gaussian hydraulic conductivity fields, Water Resour. Res., 39(3), 1051, doi:10.1029/2001WR001146, 2003. 